\title{
Globalisation and the Cultural/Creative Industries: An Assessment of Nigeria's Position in the Global Space
}

\author{
Temitope Opeyemi Falade
}

School of Media and Communication, Pan-Atlantic University

\begin{abstract}
This study provides an assessment of globalisation and its impacts on top performing creative industries in Nigeria. The prospects and contributions of the Nigerian film, music and fashion industries to the Gross Domestic Product (GDP) were highlighted in a bid to position Nigeria in the global creative space. The study adopted cognitive capitalism as its theoretical framework, and the role of culture as the major product of cognitive capitalism were explored as solutions for developing the Nigerian creative space. Empirical studies by leading research organisations and relevant agencies focused on analysing the contributions of different sectors of the economy to national growth were reviewed. A review of secondary data indicate that the contributions of Nigeria's creative industries to the global scale is on the rise. Factors that determine Nigeria's role were obtained from secondary sources and were used to form the basis for the conclusions drawn by the study. Findings from the study indicate that the creative industries in Nigeria is viable, but there is a need for more Government support and the strengthening of the socio-political environment of the country in order to attract local and foreign investments. Problems of piracy need to be addressed using copyright laws that protect intellectual property within the Nigerian film and music industry while the fashion industry requires improved infrastructure for increasing the quantity of products accessible to potential buyers and investors.
\end{abstract}

Keywords: Nollywood, Music, Fashion, Cognitive Capitalism, Creative Economy 